\title{
MODELLING CORROSION OF STEEL REINFORCEMENT IN CONCRETE: NATURAL VS. ACCELERATED CORROSION
}

\author{
E. SOLA ${ }^{*}$, J. OŽBOLT ${ }^{* \dagger}$ AND G. BALABANIĆ ${ }^{\dagger}$ \\ *University of Stuttgart \\ Institute of Construction Materials \\ Pfaffenwaldring 4, 70560, Stuttgart, Germany \\ e-mail: ozbolt@iwb.uni-stuttgart.de \\ e-mail: emiliano.sola@iwb.uni-stuttgart.de \\ ${ }^{\dagger}$ University of Rijeka \\ Faculty of Civil Engineering \\ Radmile Matejčić 3, 51000, Rijeka, Croatia \\ e-mail: gojko.balabanic@gradri.hr
}

Key words: Microplane model, Reinforced concrete, Finite elements, Hysteretic moisture behaviour, Chemo-hygro-thermo-mechanical model, Corrosion

\begin{abstract}
Chloride-induced corrosion of steel reinforcement in concrete is one of the major causes for deterioration of reinforced concrete (RC) structures. RC structures exposed to aggressive environmental conditions, such as structures close to the sea or highway bridges and garages exposed to de-icing salts, very often exhibit damage due to corrosion. Therefore, to predict durability of RC structures it is important to have a numerical tool, which is able to predict corrosion processes and their consequences for the structural safety. In order to speed up corrosion of reinforcement in concrete the experimental tests are almost always accelerated by imposing external electric potential and by adding chlorides to the concrete mix. Therefore, the corrosion rate becomes much faster than the fastest corrosion rate in nature, which can have significant consequences on the non-mechanical and mechanical processes related to the corrosion of reinforcement, i.e. the experimental results can lead to unrealistic conclusions. In the present paper recently performed experiments under accelerated conditions are simulated and compared with corrosion process that approximately corresponds to natural conditions. For the investigated geometry and environmental conditions it is shown that accelerated corrosion rate, which is approximately 20 times faster than corrosion rate under natural conditions, leads to corrosion induced damage of concrete, which is similar to the damage predicted assuming natural conditions.
\end{abstract}

\section{INTRODUCTION}

Degradation of reinforced concrete (RC) structures caused by chloride-induced corrosion is one of the major concerns for durability of RC structures [1]. Especially vulnerable are structures located in coastal marine environment or highways and garages treated with de-icing salts during winter seasons [1-2]. Consequences of chlorideinduced corrosion of steel reinforcement have negative effects on structural behaviour and involve several aspects related to the life cycle of the structure, such as serviceability, safety and structural performance. The main effect of the corrosive attack is manifested as cracking and spalling, due to the expansion of the 
corrosion products, which have greater volume than the steel. Direct and indirect costs of maintenance and repair are very high. Therefore, it is important to develop and improve numerical tools, which can realistically predict the corrosion processes and the related mechanism of deterioration in $\mathrm{RC}$ structures.

Before depassivation of reinforcement a surface layer of ferric oxide covers and protects the steel in concrete. Upon this layer being damaged or depassivated, the corrosion of reinforcement in concrete can be activated. Depassivation of the protective layer can occur by reaching a critical threshold concentration of free chloride ions near the reinforcement bar surface or as a consequence of carbonation of concrete [1]. Here is discussed only the chloride-induced type of corrosion, which is generally the most severe one. Corrosion of steel in concrete is an electrochemical process dependent on the electrical conductivity of the concrete and steel surfaces, presence and conductivity of electrolyte in the concrete and the concentration of dissolved oxygen in the pore water near the reinforcement [3-5]. Recently developed 3D chemo-hygro-thermomechanical model, which is employed in the present numerical simulations, couples the above mentioned physical and electrochemical processes with mechanical behaviour of concrete (damage). The model can simulate processes before and after depassivation of steel reinforcement in concrete under natural or accelerated corrosion conditions [6-11].

In order to calibrate and verify numerical models, experimental tests are required. However, corrosion tests under natural conditions are time consuming. Therefore, experimental tests are frequently carried out under accelerated conditions with corrosion rates that can be up to 100 or even more times faster than corrosion rates under natural conditions. This can significantly influence the test results and possibly lead to incorrect conclusions. To bring more light into the influence of accelerated corrosion on the related effects, such as corrosion induced damage of concrete, experimental tests under accelerated conditions are carried out. The first part of the paper gives a short overview of the experimental work and in the second part the numerical simulations of accelerated tests are carried out. The results are compared with simulations obtained assuming natural corrosion conditions and conclusions are drawn out.

\section{CHEMO-HYGRO-THERMO- MECHANICAL MODEL FOR CONCRETE}

In order to predict the rate of rust production and related effects, it is necessary to simulate the following physical, electrochemical and mechanical processes: (1) Transport of capillary water, oxygen and chloride through the concrete cover; (2) Immobilization of chloride in the concrete; (3) Crystallization and dissolution of free chloride as a consequence of drying and wetting of concrete as well as related hysteretic property of concrete; (4) Transport of $\mathrm{OH}^{-}$ions through electrolyte in concrete pores; (5) Cathodic and anodic polarization; (6) Transport of corrosion products in concrete and cracks; (7) Creep and shrinkage of concrete and (8) Damage of concrete due to mechanical and non-mechanical actions. Presently, there are only a limited number of coupled 3D chemo-hygro-thermo-mechanical models capable to realistically predict corrosion process in cracked concrete [6-7,12]. Recently coupled chemo-hygro-thermomechanical model for simulation of processes before and after depassivation of steel reinforcement in concrete is developed and implemented into a 3D FE code [6-10]. In the present paper the code is used to study the effect of accelerated and natural corrosion of steel reinforcement on damage of concrete specimens. Therefore, only the principal mechanical and non-mechanical involved processes are here discussed. For more detail see Ožbolt et al. [6-10] and Oršanić [11].

\subsection{Moisture transport}

During wetting and drying cycles is assumed that concrete is exposed only to changes in relative humidity, i.e. the 
macroscopic liquid flow is not included. Transport of moisture through the concrete is described as a vapour transport, which means that for non-saturated concrete at uniform temperature, moisture flux $\mathbf{j}_{w, \text { mass }}\left(\mathrm{kg} / \mathrm{m}^{2} \mathrm{~s}\right)$ may be expressed as [13]:

$$
\mathbf{j}_{w, \text { mass }}=-\delta_{v}(h) p_{v, \text { sat }} \nabla h
$$

where $h$ is the relative humidity (dimensionless), $\delta_{v}(h)$ is the water vapour permeability (s) and $p_{v, \text { sat }}$ is the water vapour saturation pressure $(\mathrm{Pa})$. The mass conservation condition, see [11], is:

$$
\frac{\partial w(h)}{\partial t}=\frac{\partial w(h)}{\partial h} \frac{\partial h}{\partial t}=\nabla \cdot\left[\delta_{v}(h) p_{v, s a t} \nabla h\right]
$$

where $t$ is the time (s), $w$ is the moisture content $\left(\mathrm{kg}_{\mathrm{H}_{2} \mathrm{O}} / \mathrm{m}^{3}\right.$ con $)$ and $\partial w / \partial h=\xi$ is the moisture capacity (derivative of the sorption isotherm). The main adsorption and desorption isotherms for the investigated concrete are taken as model input data from the experimentally obtained results. If the water content from the input isotherm data is defined in terms of mass water content, $u\left(\mathrm{~kg}_{\mathrm{H}_{2} \mathrm{O}} / \mathrm{kg}_{\text {con }}\right)$, the moisture capacity can be implemented in Eq. (1) by taking into account the density of concrete in $\mathrm{kg} / \mathrm{m}^{3}, \rho_{\text {con }}$ :

$$
\frac{\partial w(h)}{\partial h}=\rho_{c o n} \frac{\partial u(h)}{\partial h}
$$

and Eq. (2) can be rewritten in the following form:

$$
\rho_{\text {con }} \frac{\partial u(h)}{\partial h} \frac{\partial h}{\partial t}=\nabla \cdot\left[\delta_{v}(h) p_{v, s a t} \nabla h\right]
$$

The boundary conditions are defined on the exposed surface as follows:

$$
\mathbf{n} \mathbf{j}_{w, \text { mass }}=\beta_{\text {hum }}\left(h_{s}-h_{\text {env }}\right)
$$

where $\mathbf{n}$ is the unit vector normal to the exposed surface, and $\beta_{h u m}$ is the surface humidity transfer coefficient $(\mathrm{m} / \mathrm{s}), h_{s}$ is the value of the relative humidity at the exposed concrete surface and $h_{e n v}$ is the given relative humidity of the ambient air.

Values of the water vapour permeability $\delta$, for unsaturated concrete are taken from [14] according to the following expression:

$$
\delta_{v}=a_{0} f_{1}(h)
$$

where $a_{0}$ is the reference permeability at $25^{\circ} \mathrm{C}$. Function $f_{1}(h)$ reflects the moisture transfer within the adsorbed water layers and according to [15] it is estimated as follows:

$$
f_{1}(h)=\alpha+\frac{1-\alpha}{1+\left(\frac{1-h}{1-h_{c}}\right)^{4}}
$$

where $h_{c} \approx 0.75$ and $\alpha \approx 0.05$ at $25^{\circ} \mathrm{C}$.

According to Ochs et al. [16] the saturation pressure $p_{v, s a t}$ can be calculated in a temperature range from $0^{\circ} \mathrm{C}$ to $109.9^{\circ} \mathrm{C}$ with the following expression:

$$
p_{v, s a t}=610.8 \cdot e^{\frac{17.08085 \cdot \vartheta}{234.175+\vartheta}}
$$

where $\vartheta$ is the temperature in ${ }^{\circ} \mathrm{C}$.

Furthermore, for the hysteretic material, such as concrete, the moisture capacity is determined by the slope of the scanning curves which are located between the main adsorption and desorption isotherms. A simple empirical model, proposed by Pedersen [17], is used to determine the slope of the scanning curve for the adsorption conditions:

$$
\xi_{\text {hys }, a}=\frac{0.1\left(w-w_{a}\right)^{2} \xi_{d}+\left(w-w_{d}\right)^{2} \xi_{a}}{\left(w_{d}-w_{a}\right)^{2}}
$$

and for the desorption conditions:

$$
\xi_{\text {hys }, d}=\frac{0.1\left(w-w_{a}\right)^{2} \xi_{d}+0.1\left(w-w_{d}\right)^{2}}{\left(w_{d}-w_{a}\right)^{2}}
$$

where $\xi_{\text {hys }}$ is the moisture capacity, i.e. the slope of the scanning curve at a given relative humidity, $\xi_{a}=\partial w_{a} / \partial h$ and $\xi_{d}=\partial w_{d} / \partial h$ is the moisture capacity at a given relative humidity calculated from the main adsorption and desorption isotherm, respectively.

The water content during scanning between the main isotherms is determined by the following relation:

$$
w=w_{0}+\xi_{\text {hys }} \cdot \Delta h
$$

where $w_{0}$ is the initial moisture content and $\Delta h$ 
is the change in the relative humidity. More detail can be found in [18].

\subsection{Non-mechanical processes after depassivation of reinforcement}

The corrosion of steel is activated with the depassivation of the steel reinforcement in concrete. The non-mechanical processes important for the propagation stage of steel corrosion in concrete are: mass sinks of oxygen at the steel surface due to cathodic and anodic reactions, the flow of electric current through the conductive pore solution and the cathodic and anodic potentials.

The electric current through the electrolyte is a result of motion of charged particles and, if the electrical neutrality of the system and the uniform ion concentration are assumed, can be written as:

$$
\mathbf{i}=-\sigma\left(S_{w,} p_{c o n}\right) \nabla \Phi
$$

where $\sigma$ is the electrical conductivity of the concrete. For more detail see [19].

The equation for electrical charge conservation, if the electrical neutrality is accounted for and the electrical conductivity of concrete is assumed as uniformly distributed [19], reads:

$$
\nabla^{2} \Phi=0
$$

The rate of rust production $J_{r}\left(\mathrm{~kg} / \mathrm{m}^{2} \mathrm{~s}\right)$ and the mass of hydrated red rust per related surface area $\left(A_{r}\right)$ of rebar $m_{r}(\mathrm{~kg})$, respectively, are calculated as [20]:

$$
\begin{aligned}
& J_{r}=5.536 \times 10^{-7} i_{a} \\
& m_{r}=J_{r} \Delta t A_{r}
\end{aligned}
$$

where $\Delta t$ is the time interval in which the corrosion is taking place and $A_{r}$ is the corresponding surface of the steel reinforcement. The coefficient of proportionality between the anodic current density $i_{a}$ and rate of rust production $J_{r}$ is calculated using the stoichiometry of chemical reactions and Faraday's law [7-9,20].

Recent experimental investigations [21-23] have shown that the penetration of corrosion products into the pores and their relatively large ingress through the radial cracks, generated around the steel bar, has a significant effect on the development of corrosion-induced damage. The influence can be summarized as: (i) The distribution of rust and radial pressure over the anodic surface is not uniform and (ii) Damage due to expansion of corrosion products is less pronounced because part of the products "moves" away from the reinforcement surface.

The distribution of corrosion products (red rust) $R\left(\mathrm{~kg} / \mathrm{m}^{3}\right.$ of pore solution) into the pores and through the cracks in concrete has been mathematically formulated as a convective diffusion problem:

$\theta_{w} \frac{\partial R}{\partial t}=\nabla \cdot\left[\theta_{w} D_{r} \nabla R\right]+D_{w}\left(\theta_{w}\right) \nabla \theta_{w} \nabla R$

in which $D_{r}$ is the diffusion coefficient $\left(\mathrm{m}^{2} / \mathrm{s}\right)$ of corrosion products. It is important to note that the previous equation does not directly describe the transport of red rust, but rather the distribution of the rust formed in the concrete pores and cracks as a consequence of soluble species (which can dissolve in concrete pore solution and subsequently migrate in the pores and cracks) reacting with oxygen in the pore water [23].

\section{ACCELERATED CORROSION EXPERIMENT AND 3D FE ANALYSIS}

Recently an extensive experimental test program was initiated, which is still in progress, to calibrate the parameters needed for the above mentioned 3D chemo-hygrothermo-mechanical model. Samples used in the experimental tests are cylinders with castin reinforcement bars of different sizes. They are exposed to accelerated corrosion under different laboratory controlled conditions by imposing an external electric potential. In addition, chlorides are added to the concrete mix to accelerate depassivation of reinforcement. Moreover, experiments under natural corrosion conditions are also underway. The casting of the samples and the experiments are carried out at the University of Stuttgart, Institute of Construction 
Materials.

\subsection{Geometry and material properties}

The samples discussed in the present paper are concrete cylinders with a diameter of $50 \mathrm{~mm}$ and height of $150 \mathrm{~mm}$, with a cast-in steel bar of $8 \mathrm{~mm}$ in diameter and cover of $21 \mathrm{~mm}$, as shown in Fig. 1.
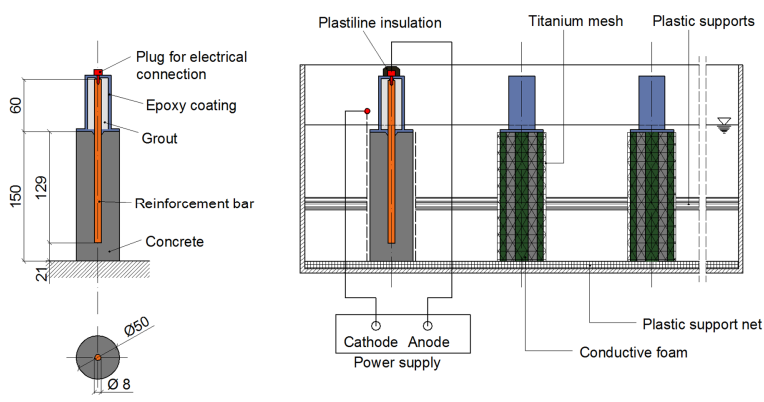

Figure 1: Geometry of the specimen and details of the accelerated corrosion tests (measures in $\mathrm{mm}$ ).

Concrete is manufactured using Portland cement CEM I $42.5 \mathrm{~N}$ and water/cement ratio of 0.7. Siliceous sand and aggregates were used with a maximum aggregate size of $8 \mathrm{~mm}$. Approximately $2.5 \%$ of $\mathrm{NaCl}$ by weight of cement was added to the mixture in order to accelerate depassivation of steel. The specimens were cast in PVC cylindrical molds held from a wooden assembly with an appropriate hole to fix position of the steel bar and assuring the designed embedment length of the reinforcement.

The specimens were cured 7 days under constant temperature of $20^{\circ} \mathrm{C}$ and relative humidity (RH) of $100 \%$. Subsequently they were stored in a temperature controlled chamber at $20^{\circ} \mathrm{C}$ with $\mathrm{RH}$ of $60 \%$. The uniaxial compressive strength of concrete was measured before testing on standard cubes of 150x150x $150 \mathrm{~mm}$. The average strength (three specimens) is $f_{c}=40 \mathrm{MPa}$. Based on $f_{c}$ the concrete properties were estimated as: Young's modulus $E_{c}=31.6 \mathrm{GPa}$, Poisson's ratio $v=0.18$, tensile strength $f_{t}=3.10 \mathrm{MPa}$ and fracture energy $G_{F}=55 \mathrm{~J} / \mathrm{m}^{2}$. Mass density of concrete is assumed to be $\rho_{c}=2400 \mathrm{~kg} / \mathrm{m}^{3}$. The reinforcement bar is normal steel with the following properties: Young's modulus $E_{c}=210.0 \mathrm{GPa}$, Poisson's ratio $v=0.33$ and mass density $\rho_{s}=7800 \mathrm{~kg} / \mathrm{m}^{3}$.

\subsection{Accelerated corrosion test set-up and testing environment}

After curing, the samples were dried and coating of grout and epoxy resin was applied onto external part of the reinforcement. In order to accelerate the corrosion process, an imposed constant potential was applied between the rebar (anode) and a cylindrical shell of platinized titanium mesh (cathode), located around the lateral surface of the specimen. Four stripes of conductive foam, at $90^{\circ}$ to each other, were used to electrically connect the external titanium mesh with the concrete surface (see Fig. 1). To investigate the influence of corrosion rate, two different voltages were used. During the experiment readings of current were continuously recorded measuring the drop of voltage, over a resistance unit of $10 \Omega$, and were performed by a digital multimeter data acquisition and data logging system, KEITHLEY 2701. Specimens were exposed to cyclic wetting/drying regime, 1 day of wetting by $2.5 \% \mathrm{NaCl}$ solution, followed by 6 days of drying at relative humidity of approximately $60 \%$. As mentioned above, because of the extensive experimental program and numerous specimens, here are discussed only the results obtained for the smallest specimens, with reinforcement bar of $8 \mathrm{~mm}$ and concrete cover of $21 \mathrm{~mm}$, exposed to wetting/drying cycles with two imposed potentials, $100 \mathrm{mV}$ (specimen $\mathrm{A}, \mathrm{B}, \mathrm{C}$ ) and $500 \mathrm{mV}$ (specimen D, E, F).

\subsection{Numerical analysis of experimental tests}

The main aim of the numerical study is to verify and calibrate the above discussed 3D chemo-hygro-thermo-mechanical model for the case of accelerated corrosion. Furthermore, it should be investigated the influence of water content and concrete conductivity on current density and crack pattern. Moreover, the influence of the imposed electric potential and related current density on the transport of rust and related 
crack pattern should be studied. Finally, based on the calibrated model parameters for accelerated corrosion and the comparison between natural and accelerated corrosion, should be possible to highlight the differences for an objective evaluation of test results obtained from accelerated corrosion.

The geometry of the specimen is the same as in the experiment except that the length of only $50 \mathrm{~mm}$ is simulated assuming axisymmetric conditions (geometrical, mechanical and environmental). The finite element discretization is performed using solid 8-node finite elements and as localization limiter crack band method is used [24]. The mechanical model for concrete is based on the microplane model [25]. In contrast to mechanical part, in the non-mechanical part of the model transient finite element analysis based on the direct implicit integration scheme is carried out. It is assumed that the entire length of the steel bar is activated as anode (depassivated) at the start of the analysis. Consequently, only water content, electric potential, current density at the surface of reinforcement, transport of rust through pores and cracks of concrete are computed. Note that corrosion rate at the surface of reinforcement is calculated from computed electrical current density according to Eq. (14).

The parameters of the hysteretic moisture model were calibrated from experimental results obtained for two different levels of imposed electric potential: 100 and $500 \mathrm{mV}$. The used sorption isotherms (concrete $w / c=0.65$ ) are plotted in Fig. 2 (top) and the corresponding parameters are listed in Table 1 (isothermal conditions, temperature $=20^{\circ} \mathrm{C}$ ).

In Fig. 2 (bottom) is also illustrated the change of relative humidity and water content during 7 weekly cycles of wetting and drying as result of the numerical simulation, performed for $100 \mathrm{mV}$ according to the wetting/drying regime exposure of the experimental tests. The water content is expressed in terms of mass water content and the numerical data is taken for the depth of $21 \mathrm{~mm}$ from the exposed surface, which corresponds to the interface between the steel reinforcement and concrete. Based on the experimental values of current density, the analyses are assumed to start at $60 \% \mathrm{RH}$ from the adsorption curve. In the first wetting phase there is a large increase of water content, following the adsorption isotherm, before showing hysteretic behaviour (scanning loops), which is more pronounced in the presence of concrete damage. The predicted damage (crack after 17 days in case of $100 \mathrm{mV}$ ) influences the non-mechanical processes through the continuous update of the model parameters, such as water vapour permeability, whose dependency on crack width is based on experimental results for water permeability in cracked concrete [2627]. It can be also noted that the scanning curves cover a relatively large $\mathrm{RH}$ range. This is due to the high w/c ratio and the fact that the corresponding total mass water content is increasing in time.

Furthermore, electrical conductivity of concrete (see Table 2) was calibrated based on the experimentally measured average current density and from the experimentally measured conductivity on fully saturated concrete cube specimens using the "Two Electrodes Method" (TEM). The conductivity is relevant for the computation of current density, especially in chloride contaminated concrete [28].

As discussed in Ožbolt et al. [8-10] for the corrosion induced damage the expansion factor of rust and its transport through concrete play an important role. In the used model transport of rust through pores of concrete and cracks is modeled as diffusion-convection governed process (mathematical interpretation). Note that from the physical point of view the rust is not transported, instead, ions are transported and corrosion products are generated in the pores around the reinforcement bar and in cracks. The relation between diffusivity of rust and crack width is obtain based on the calibration of the experimental data.

The initial diffusion coefficient for uncracked concrete, obtained by comparing the experimental corrosion time for cracking, is set to $D_{r}=32.0 \times 10^{-16} \mathrm{~m}^{2} / \mathrm{s}$ in case of $100 \mathrm{mV}$ applied and $D_{r}=95.0 \times 10^{-16} \mathrm{~m}^{2} / \mathrm{s}$ in case of $500 \mathrm{mV}$. The difference can be explained on 
the base of the amount of corrosion products produced in time, which diffuse in concrete pores and voids. In case of high applied current density more products are accommodated in the neighborhood of the reinforced and thus more of them penetrate into pores of concrete.
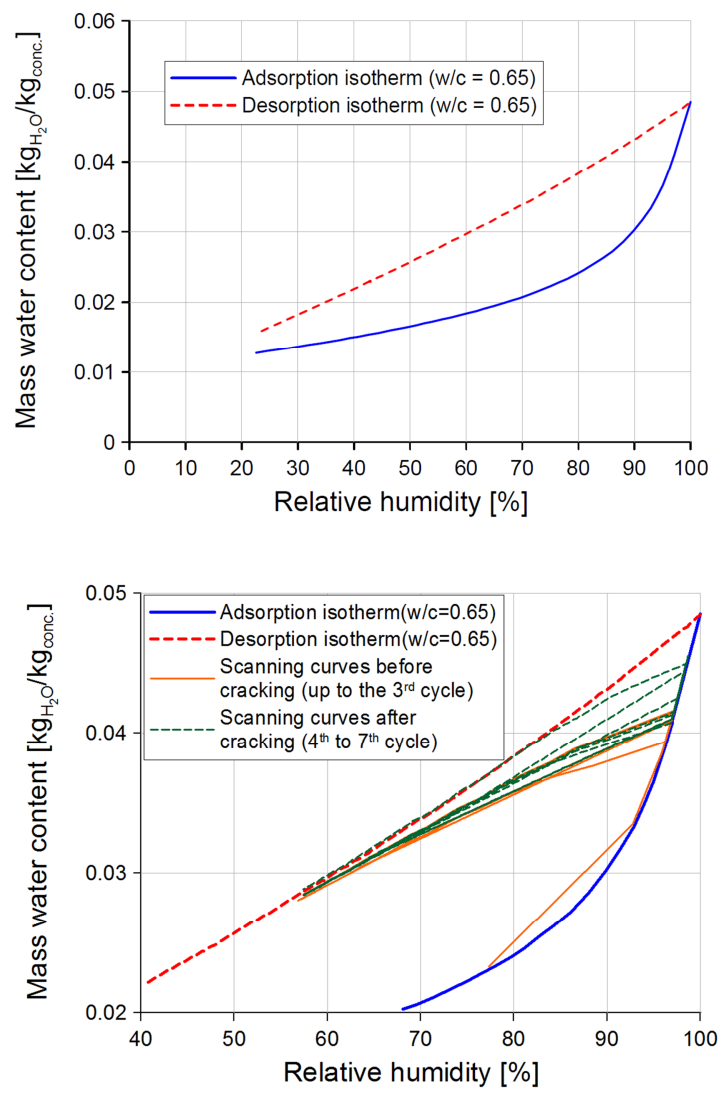

Figure 2: Input main adsorption and desorption curves from the experiments by Hansen [29] for concrete with $\mathrm{w} / \mathrm{c}=0.65$ (top) and calculated scanning curves during the 7 weekly cycles of wetting and drying at the depth of $21 \mathrm{~mm}$ before and after cracking, under an imposed potential of $100 \mathrm{mV}$ (bottom).

\subsection{Characterization of the corrosion products}

Corrosion products forming around the steel reinforcement in concrete are significantly influenced by dissolved oxygen in water, chloride concentration, and environmental condition. Especially in case of imposed potential (relatively high corrosion current density and admixed chlorides) the type, the rate and the distribution of products are highly influenced. They are, in comparison with products generated under natural conditions (red rust), significantly different. Their relative volume increase, in comparison with steel, differs depending on the type and varies from 2 up to the value of 7 . In order to correctly interpret the results in case of anodic polarization and make them comparable with the natural conditions, corrosion products formed in the presented experiments are examined with Raman spectroscopy. Furthermore, their distribution in the vicinity of the reinforcement and in the cracks is investigated by means of microscopic analyses.

The measurements were performed on thin sections with a Raman microscope of the company Horiba, model XploRa. Firstly, they were visually examined with magnification factor 10 and compared with the microscope photos of the samples. Later, after selecting the measuring ranges, certain points were investigated by employing spectroscopy with magnification factor 50. The measurements were always carried out starting from the steel area and then following the concrete cracks filled with iron minerals. The parameters of the Raman spectra were set in appropriate software, the spectra stored electronically and then evaluated with a Data-Processing Software. Microscope photos of the measuring points were taken as examples to illustrate the distribution of mineral contents.

The analysis shows the presence of a dense layer of products, which is mostly constituted of one or several mixed oxy-hydroxides. As can be seen from Figs. 3 and 4, the major corrosion products of this layer were identified as goethite $(\alpha-\mathrm{FeOOH})$ in case of $100 \mathrm{mV}$ and akaganeite $(\beta-\mathrm{FeOOH})$ in case of $500 \mathrm{mV}$ applied. These kind of products are generally found when enough chlorine is present in the dense layer [30].

Considering the investigations on morphology and distribution of corrosion products in the vicinity of the reinforcement surface, the volume expansion factor of rust is assumed to be congruent with $\alpha_{r}=\rho_{s} / \rho_{r}=4.0$ in natural conditions (red rust) and $\alpha_{r}=\rho_{s} / \rho_{r}=1.9$ in accelerated conditions (goethite and akaganeite). 

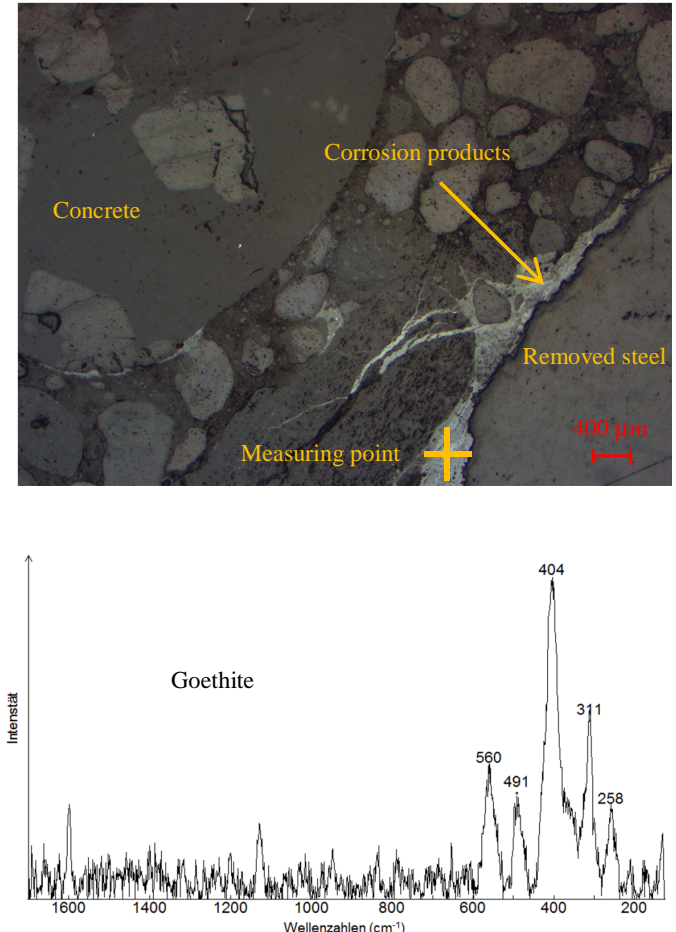

Figure 3: Microscopic picture of a thin section of the transition zone concrete-rust-steel for an imposed electric potential of $100 \mathrm{mV}$ (top) and corresponding Raman spectrum of the measuring point (bottom).
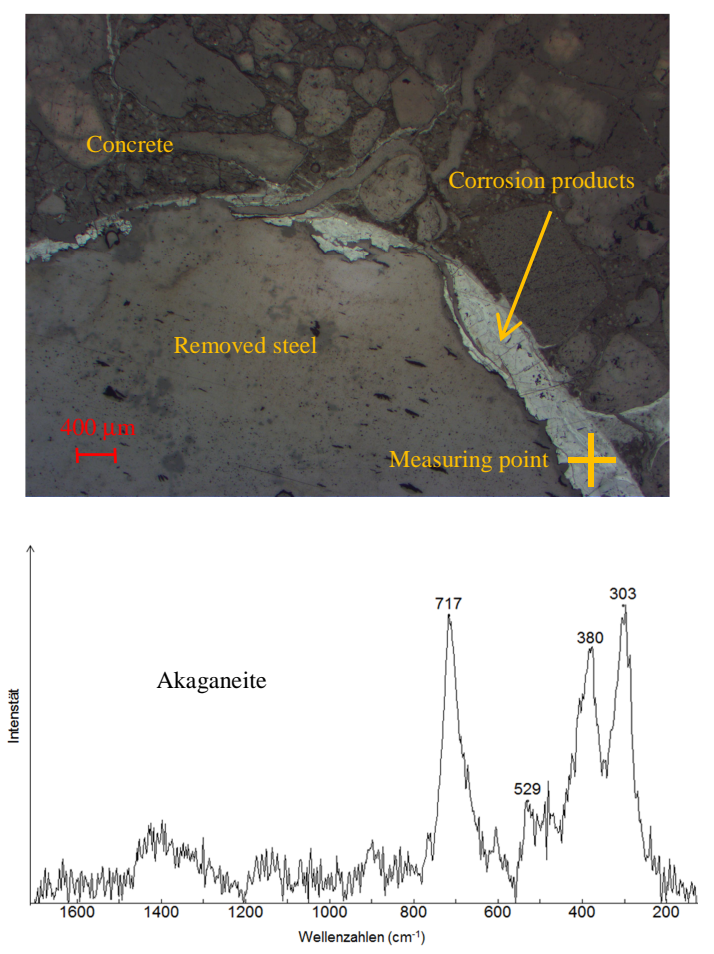

Figure 4: Microscopic picture of a thin section of the transition zone concrete-rust-steel for an imposed electric potential of $500 \mathrm{mV}$ (top) and corresponding Raman spectrum of the measuring point (bottom).
Table 1: Model parameters relevant for computation of relative humidity

\begin{tabular}{|c|c|}
\hline \multicolumn{2}{|c|}{ Hysteretic moisture model for concrete } \\
\hline Sorption isotherms & $\mathrm{w} / \mathrm{c}=0.65$ \\
\hline Water vapour permeability [s] & $5.0 \times 10^{-10}$ \\
\hline Surf. humidity trans. Coeff $[\mathrm{m} / \mathrm{s}]$ & $4.5 \times 10^{-6}$ \\
\hline
\end{tabular}

Table 2: Electrical conductivity of concrete $(\mathrm{w} / \mathrm{c}=0.7)\left[10^{-3} \Omega^{-1} \mathrm{~m}^{-1}\right]$

\begin{tabular}{ccc}
\hline Saturation & $\boldsymbol{\sigma}_{\text {natural }}$ & $\boldsymbol{\sigma}_{\text {accelerated }}$ \\
\hline 50 & 2.75 & 8.75 \\
\hline 55 & 3.00 & 9.54 \\
\hline 60 & 4.28 & 13.61 \\
\hline 65 & 8.70 & 27.67 \\
\hline 70 & 9.52 & 30.27 \\
\hline 75 & 10.50 & 33.39 \\
\hline 80 & 11.50 & 36.57 \\
\hline 85 & 12.50 & 39.75 \\
\hline 90 & 13.50 & 42.93 \\
\hline
\end{tabular}

\subsection{Comparison between numerical and test results}

The average experimental and numerical values of anodic current density-history curves for three different specimens with imposed potential of $100 \mathrm{mV}$ (specimen A, B, C) and $500 \mathrm{mV}$ (specimen D, E, F) are plotted in Fig. 5. The experimental data are average values on the anodic surface area calculated using measured current intensity. As can be seen, the numerical model is able to realistically simulate anodic current density time history curve. The analysis and the experiment exhibit sudden increase of current density that is related with sudden wetting of concrete cylinder (see hysteretic behaviour of concrete in Fig. 2). Subsequently the water content decreases and current density gradually decreases as well (6 days drying). As expected, with increase of imposed electric potential from $100 \mathrm{mV}$ to $500 \mathrm{mV}$, average current density increases approximately proportionally with imposed electric potential, i.e. with the factor of five. 

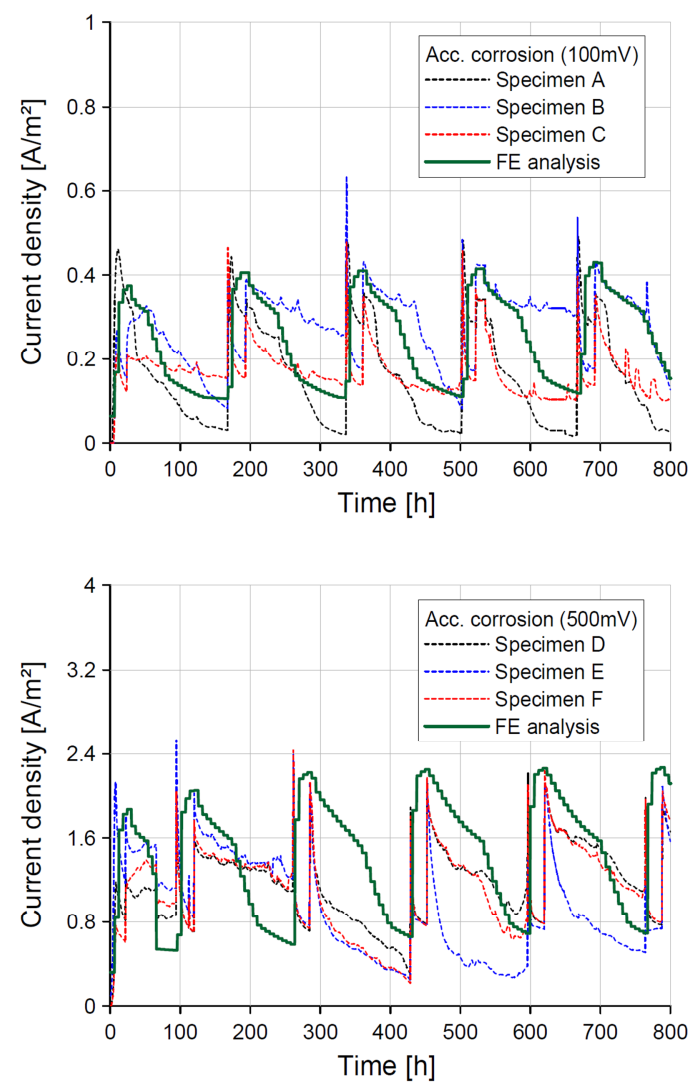

Figure 5: Time dependent distribution of the average anodic current density for an imposed electric potential of $100 \mathrm{mV}$ (top) and 500mV (bottom).

It can be noted that the moisture content and the anodic current density are strongly influenced by the corrosion induced cracks, which leads to ingress of water into specimen and increase of saturation in un-cracked concrete. Consequently, with increasing wetting-drying cycles, current density tends to increase, especially in case of higher imposed potential $(500 \mathrm{mV})$. Moreover, as already mentioned, once the crack is generated the water content gradually increases in time. This accelerates the transport of rust from the reinforcement surface through the cracks into direction of concrete specimen surface. It has to be noticed that during wetting periods, in which the specimens are completely under water, the analysis does not indicate significant change in current density, as in experimental tests. This is probably a consequence of the assumption that the accelerated corrosion process is independent of the oxygen content.

Fig. 6 shows the observed and calculated crack patterns (crack initiation). For lower and higher imposed potential in the experiment the first crack at the surface of the cylinder (crack width $=0.05 \mathrm{~mm}$ ) appeared after 20 and 6 days, respectively, and in the analysis after 17 and 4 days, respectively. Having on mind the complexity of the problem this is relatively in good agreement and the crack patterns are also similar. There is one dominant vertical crack in the experiment and in the analysis. Furthermore, it can be seen that there is a large amount of rust at the concrete surface. This indicates that a lot of corrosion products are transported from the reinforcement through cracks onto the surface of the concrete cylinder.
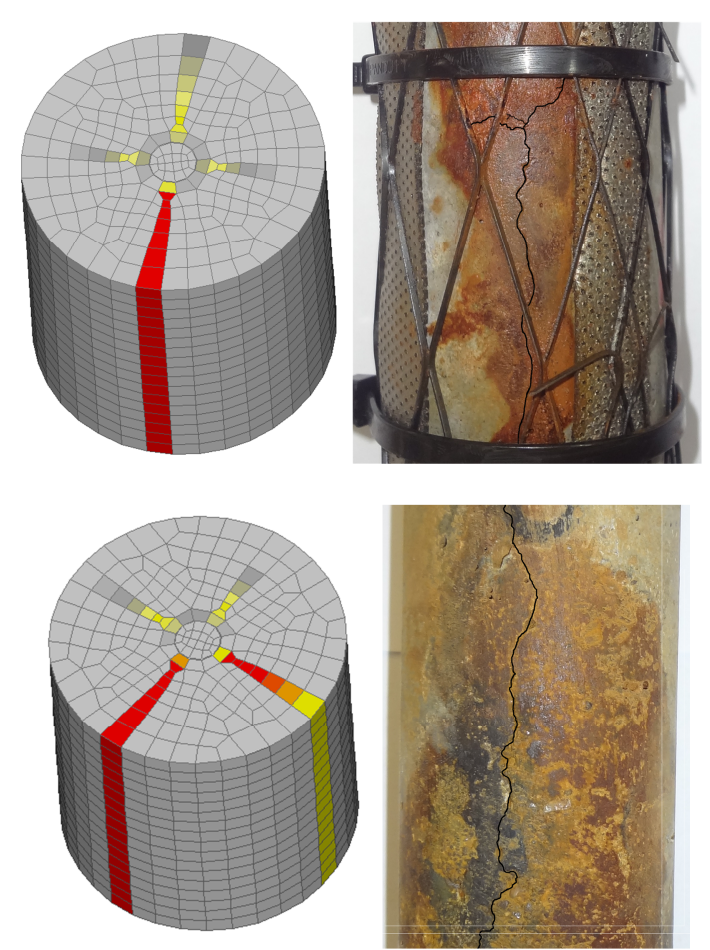

Figure 6: Predicted (crack initiation at surface) and experimentally observed crack patterns for potential of $100 \mathrm{mV}$ (top) and $500 \mathrm{mV}$ (bottom) (red = crack opening $\geq 0.05 \mathrm{~mm})$.

\section{NATURAL CORROSION - EXPERIMENT AND 3D FE ANALYSIS}

In order to be able to investigate the difference between corrosion induced damage between natural and accelerated corrosion the above specimen is numerically analyzed assuming natural corrosion conditions. Only 
active phase of corrosion is computed, i.e. the phase after depassivation of steel. It is assumed that the concrete cylinder is exposed to the constant air temperature of $20^{\circ} \mathrm{C}$ with humidity conditions which correspond to Stuttgart, i.e. variation of air relative humidity in the range from $63 \%$ (May) up to maximum $80 \%$ (December). To calculate corrosion rate it is necessary to compute distribution of relative humidity, oxygen and electric potential. Electric potential is computed based on the Butler-Volmer kinetics [10] assuming anodic and cathodic surfaces as shown in Fig. 7 (top). The volume expansion factor is assumed to be congruent with $\alpha_{r}=\rho_{s} / \rho_{r}=4.0$ (red rust) and diffusivity for rust transport is set to $D_{r}=2.2 \times 10^{-16} \mathrm{~m}^{2} / \mathrm{s} \quad[10]$. The electrical conductivity of concrete used in the analysis is specified in Table 2. More details related to other relevant model parameters can be found in [8-10]. Note that in contrast to accelerated corrosion for the natural corrosion also creep of concrete is accounted for [31].

Fig. 7 (top) shows typical crack pattern at crack initiation, 180 days after depassivation. The time history of average current density at the anodic-cathodic transition zone is plotted in Fig. 7 (bottom). As can be seen, maximum current density reaches approximately the value of $0.16 \mathrm{~A} / \mathrm{m}^{2}$, which is, for the assumed concrete quality $(\mathrm{w} / \mathrm{c}=0.70)$ and given environmental conditions, a realistic value. Compared to accelerated corrosion, the computed corrosion rate is approximately $3(100 \mathrm{mV})$ and $15(500 \mathrm{mV})$ times higher. In spite of this, the computed crack pattern is very similar to that obtained for the accelerated corrosion. There are two reasons for this: (i) In case of accelerated corrosion goethite and akaganeite are produced, which have expansion factor $\left(\rho_{s} / \rho_{r}=1.9\right)$ lower than the red rust $\left(\rho_{s} / \rho_{r}=4.0\right)$ produced in case of natural conditions; (ii) In accelerated corrosion there is relative large amount of water present, which accelerates transport of rust and consequently reduce the pressure of rust around the reinforcement bar.
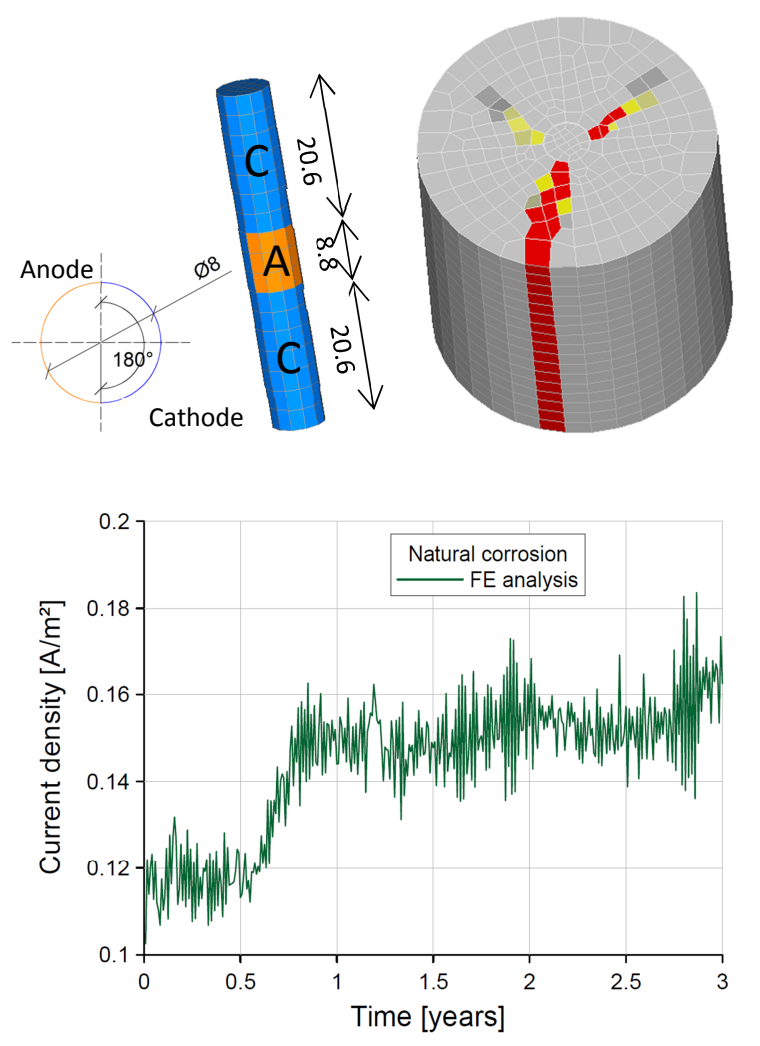

Figure 7: Assumed position of anode and cathode [mm], first visible crack at concrete surface (180 days, red $=0.05 \mathrm{~mm}$ crack width) and time history of current density at the anode-cathode transition zone.

\section{ACKNOWLEDGMENT}

The authors are grateful for the financial supports of "Deutsche Forschung Gemeinschaft" (DFG, Grant Nr. 601984) and "Croatian Science Foundation" (HRZZ, Grant Nr. 9068).

\section{CONCLUSIONS}

In the present paper experimental tests and numerical analysis of accelerated corrosion of steel reinforcement embedded in concrete cylinders are performed. The results are compared with numerical results assuming natural corrosion conditions. Based on the results the following conclusions can be drawn out. (1) The recently proposed coupled $3 \mathrm{D}$ chemo-hygro-thermo-mechanical model is able to realistically simulate experimental tests on accelerated corrosion of steel reinforcement in concrete. (2) Computed current density and related time of cracking and crack patterns are similar to the experimentally observed ones. 
(3) The transport of rust through cracks in concrete plays important role in corrosion induced damage of concrete. This is especially true if there is relatively high saturation of concrete. (4) In case of accelerated corrosion different types of products are identified with expansion factor lower of that observed in case of natural corrosion. In particular goethite $(\alpha-$ $\mathrm{FeOOH})$ and akaganeite $(\beta-\mathrm{FeOOH})$ were found in case of imposed potentials $100 \mathrm{mV}$ and $500 \mathrm{mV}$, respectively. (5) Although for natural corrosion, current density is up to 20 times lower than in accelerated corrosion $(500 \mathrm{mV})$, the crack patterns are very similar. Therefore it can be concluded that for the present geometry and environmental exposure, accelerated conditions with imposed electric potential up to $500 \mathrm{mV}$ yields to results that are comparable with the results obtained assuming natural corrosion. (6) Further experimental and numerical work is needed in order to investigate the influence of accelerated corrosion for different geometries and environmental conditions.

\section{REFERENCES}

[1] Tuutti K. 1993. Corrosion of steel in concrete. Technical report. Stockholm.

[2] Cairns JW. 1998. State of the art report on bond of corroded reinforcement. Technical report No. CEB-TG-2/5.

[3] Bažant ZP. 1979. Physical Model for Steel Corrosion in Concrete Sea Structures Theory. J Struct Div-ASCE, 105(6),11371153.

[4] Glasstone S. 1964. An introduction to electrochemical behaviour of steel in concrete. ACI J, 61,177-188.

[5] Page CL, Treadway KWJ. 1982. Aspects of the electrochemistry of steel in concrete. Nature, 297, 109-15.

[6] Ožbolt J, Balabanić G, Periškić G, Kušter M. 2010. Modelling the effect of damage on transport processes in concrete. Constr Build Mater, 24(9), 1638-1648.

[7] Ožbolt J, Balabanić G, Kušter M. 2011.
3D Numerical modelling of steel corrosion in concrete structures. Corros Sci, 53(12), 4166-4177.

[8] Ožbolt J, Oršanić F, Balabanić G, Kušter M. 2012. Modeling damage in concrete caused by corrosion of reinforcement: coupled 3D FE model. Int J Fract, 178(1-2), 233-244.

[9] Ožbolt J, Oršanić $F$, Kušter $M$, Balabanić G. 2012. Modelling bond resistance of corroded reinforcement. Bond in Concrete 2012. Proceedings of the International Conference, p. 437-444.

[10] Ožbolt J, Oršanić F, Balabanić G. 2014. Modeling pull-out resistance of corroded reinforcement in concrete: Coupled threedimensional finite element model. Cement and Concrete Composites, 46, 41-55.

[11] Oršanić F. 2015. Chemo-hygro-thermomechanical model for simulation of corrosion induced damage in reinforced concrete. Dissertation. Stuttgart.

[12] Marsavina L, Audenaert K, Schutter G de, Faur N, Marsavina D. 2009. Experimental and numerical determination of the chloride penetration in cracked concrete. Constr Build Mater, 23(1), 264-274.

[13] Kwiatkowski J, Woloszyn M, Roux JJ. 2009. Modeling of hysteresis influence on mass transfer in building materials. Building and Environment, 44(3), 633642.

[14] Bažant ZP, Kaplan MF. 1996. Concrete at high temperature. Longman. Essex, UK.

[15] Bažant ZP, Najjar LJ. 1972. Nonlinear water diffusion in nonsatured concrete. Matériaux et Construction, 5(1), 3-20.

[16] Ochs, F., Heidemann, W., \& MüllerSteinhagen, H. 2008. Effective thermal conductivity of moistened insulation materials as a function of temperature. International Journal of Heat and Mass Transfer, 51(3), 539-552.

[17] Pedersen CR. 1990. Combined heat and moisture transfer in building constructions (Vol. 214). Thermal Insulation Laboratory, Technical University of Denmark.

[18] Ožbolt, J., Oršanić, F. \& Balabanić, G. 2016. Modeling Influence of Hysteretic 
Moisture Behavior on Distribution of Chlorides in Concrete. Cement and Concrete Composites, 67, 73-84.

[19] Newman J., Thomas-Alyea K.E. 2004. Electrochemical Systems, WileyInterscience.

[20] Martín - Pérez B. 1999. Service life modelling of $R C$ highway structures exposed to chlorides. Dissertation. University of Toronto.

[21] Fischer C. 2012. Beitrag zu den Auswirkungen der Bewehrungsstahlkorros ion auf den Verbund zwischen Stahl und Beton. Dissertation. Stuttgart.

[22] Fischer C, Ožbolt J. 2012. Influence of bar diameter and concrete cover on bond degradation due to corrosion. Bond in Concrete 2012. Proceedings of the International Conference, p. 445-451.

[23] Wong HS, Zhao YX, Karimi AR, Buenfeld NR, Jin WL. 2010. On the penetration of corrosion products from reinforcing steel into concrete due to chloride-induced corrosion. Corros Sci, 52(7), 2469-2480.

[24] Bažant ZP, Oh BH. 1983. Crack band theory for fracture of concrete. Mater Struct, 16(93), 155-177.

[25] Ožbolt J, Li Y, Kožar I. 2001. Microplane model for concrete with relaxed kinematic constraint. Int J Solids Struct, 38(16), 2683-2711.

[26] Wang, K., Jansen, D. C., Shah, S. P., \& Karr, A. F. 1997. Permeability study of cracked concrete. Cement and Concrete Research, 27(3), 381-393.

[27] Aldea, C. M., Ghandehari, M., Shah, S. P., \& Karr, A. 2000. Estimation of water flow through cracked concrete under load. ACI Materials Journal, 97(5).

[28] Osterminski K, Schieß1 P. 2012. Vollprobabilistische Modellierung von Bewehrungskorrosion. Ein Beitrag zur Dauerhaftigkeitsbemessung. Projekt D. Deutscher Ausschuss für Stahlbeton. Berlin.

[29] Hansen KK. 1986. Sorption Isotherms. Acatalogue. Technical University of Denmark.

[30] Chitty, W. J., Dillmann, P., L'Hostis, V.,
\& Lombard, C. 2005. Long-term corrosion resistance of metallic reinforcements in concrete-a study of corrosion mechanisms based on archaeological artefacts. Corrosion Science, 47(6), 1555-1581.

[31] Ožbolt, J. and Reinhardt, H.W. 2001. Three-dimensional finite element model for creep-cracking interaction of concrete. Proceedings of the sixth international conference CONCREEP-6, Ed. By Ulm, Bažant \& Wittmann, 221-228. 